\title{
Peramalan Penjualan Pada Usaha Kecil Menengah (UKM) Roti Sania Dengan Menggunakan Program POM QM
}

\author{
Henny Yulius ${ }^{1}$, Yadi Prawinata ${ }^{2}$, Indah Permatasari ${ }^{3}$ \\ Email : henny_yulius27@yahoo.com
}

\begin{abstract}
ABSTRAK
Peramalan merupakan upaya memperkirakan apa yang terjadi pada masa mendatang berdasarkan data pada masa lalu, berbasis pada metode ilmiah dan kualitatif yang dilakukan secara sistematis. Peramalan juga menunjukkan perkiraan yang akan datang terjadi pada suatu keadaan tertentu agar tidak terjadi penumpukan stok atau kekurangan stok sehingga dengan metode peramalan dapat menjadi acuan dalam menentukan jumlah produksi.Hal tersebut sangat menguntungkan mengingat masyarakat sekarang mempunyai kebutuhan yang beraneka ragam dengan tingkat daya beli yang tinggi. Roti SANIA merupakan salah satu pabrik roti yang terdapat diwilayah padang, Sumatera Barat yang mempunyai tujuan untuk berusaha memenuhi berbagai macam kebutuhan konsumen wilayah Padang dan sekitarnya. Dari hasil pengolahan data demand yang diambil dengan melakukan survey lapangan pada Pabrik Roti Sania Bakery, didapatkan hasil, baik dengan menggunakan program POM QM menghasilkan hasil forecast/peramalan yang hampir sama. Untuk menentukan metode mana yang akan dipakai dalam peramalan penjualan maupun permintaan roti SANIA, maka dipakailah metode yang memiliki SEE yang terkecil.
\end{abstract}

Kata kunci : Peramalan, permintaan, metode peramalan.

\section{PENDAHULUAN}

\section{I.1 Latar Belakang Masalah}

Dunia perekonomian kini banyak diisi dengan industri-industri yang jenisnya sekarang mulai beraneka ragam dan salah satu jenis perindustrian yang mempunyai peluang bisnis cukup banyak adalah usaha Pembuatan Roti. Hal ini dapat dilihat dengan banyaknya pusat perbelanjaan seperti minimarket, supermarket, dan sebagainya. Hal tersebut sangat menguntungkan mengingat masyarakat sekarang mempunyai kebutuhan yang beraneka ragam dengan tingkat daya beli yang tinggi. Roti SANIA merupakan salah satu pabrik roti yang terdapat diwilayah padang, Sumatera Barat yang mempunyai tujuan untuk berusaha memenuhi berbagai macam kebutuhan konsumen wilayah Padang dan sekitarnya

Peramalan merupakan upaya memperkirakan apa yang terjadi pada masa mendatang berdasarkan data pada masa lalu, berbasis pada metode ilmiah dan kualitatif yang dilakukan secara sistematis.

Peramalan menunjukkan perkiraan yang akan datang terjadi pada suatu keadaan tertentu agar tidak terjadi penumpukan stok atau kekurangan stok sehingga dengan metode peramalan dapat menjadi acuan dalam menentukan jumlah produksi.

Berdasarkan uraian tersebut penulis mengambil judul "Analisis Peramalan jumlah kebutuhan terhadap produksi Roti SANIA".

\subsection{Rumusan Masalah}

Berdasarkan latar belakang tersebut diatas, maka masalah yang akan dibahas dirumuskan sebagai berikut :

1. Metode peramalan apa yang dapat meminimumkan kesalahan peramalan kebutuhan dalam proses produksi pada pabrik roti SANIA ? 
2. Bagaimana peramalan kebutuhan pada pabrik roti SANIA pada periode-periode berikutnya?

3. Bagaimana memilih metode yang tepat untuk memaksimumkan jumlah produksi pabrik roti ?

\subsection{Batasan Masalah}

Agar pembahasan penelitian ini lebih terfokus maka perlu diadakan pembatasan penelitian. Batasan permasalahan penelitian adalah:

1. Model yang digunakan dalam peramalan permintaan pada roti SANIA adalah Moving Average 2, Weight Moving Average 2, Metode Konstan dan Exponential Smooting (ES)

2. Peramalan ditekankan pada peramalan permintaan barang jadi disini peramalan penjualan roti sania.

\subsection{Tujuan Penelitian}

Adapun tujuan dari penelitian sebagai berikut:

1. Untuk mengetahui metode peramalan yang tepat sehingga dapat meminimumkan kesalahan peramalan persediaan bahan baku dan permintaan dalam proses produksi pada pabrik roti SANIA.

2. Untuk mengetahui bagaimana peramalan kebutuhan pada pabrik roti SANIA pada periode-periode berikutnya?

\subsection{Manfaat Penelitian}

Penelitian ini diharapkan dapat memberikan informasi kepada pihak industri Pabrik Roti "SANIA" tentang model dan ramalan jumlah permintaan roti selama 1 periode kedepan sehingga dapat memenuhi jumlah permintaan dengan baik.

\section{TINJAUAN PUSTAKA}

\subsection{Pengertian Peramalan}

Peramalan (forecasting) merupakan suatu kegiatan untuk mengetahui apa yang akan terjadi di masa yang akan datang menggunakan dan mempertimbangkan data dari masa lampau. suatu fungsi bisnis yang berusaha memperkirakan permintaandan penggunaan produk sehingga produk-produk itu dapat dibuatdalam kuantitas yang tepat. Dengan demikian peramalan merupakan suatu dugaan terhadap permintaan yang akan datangberdasarkan pada beberapa variabel peramal, sering berdasarkan data deret waktu historis.

Dengan digunakannya peralatan metode-metode peramalan maka akan memberikan hasil peramalan yang lebih dapat dipercaya ketetapannya. Oleh karena masingmasing metode peramalan berbeda-beda, maka penggunaannya harus hati-hati terutama dalam pemilihan metode untuk penggunaandalam kasus tertentu. Peramalan dapat menggunakan teknik-teknik peramalan yang bersifat formal maupun informal. Aktivitas peramalan ini biasa dilakukan oleh departemen pemasaran dan hasil-hasil dariperamalan ini sering disebut sebagai ramalan permintaan.

\subsection{Metode Peramalan}

\subsubsection{Metode Kuantitatif}

Penggunaan metode ini didasari ketersediaan data mentah disertai serangkaian kaidah matematis untuk meramalkan hasil di masa depan. Terdapat beberapa macam model peramalan yang tergolong metode kualitiatif, yaitu:

Metode peramalan yang akan digunakan adalah metode kuantitatif. Metode kuantitatif dapat digolongkan menjadi dua teknik :

1. Teknik Deret Berkala (Time Series)

Metode yang sering dipakai dalam Teknik Deret Berkala :

a.Metode Smoothing

b.Metode Dekomposisi 
Penelitian Bidang Komputer Sains dan Pendidikan Informatika V1.i1(64-69)

Metode-metode yang termasuk metode smoothing adalah :

1. Metode Average (rataan)

Metode ini terdiri dari;

1. Metode Rata-rata (Simple Average)

Persamaan metode rata-rata yaitu $X=\sum_{i=1}^{T} \frac{X_{i}}{T}=F_{T+1}$

2. Single Moving Avarage

Persamaan single moving average adalah ;

$F_{T+1}=X=\sum_{i=n}^{T+(n-1)} \frac{X_{i}}{T}$

3. Double Moving Average

a. Metode Exponential Smoothing

1. Single

Exponential

Smoothing.

$F_{t+1}=\alpha \cdot X_{t}+(1-\alpha) F_{t}$ Atau

$F_{t+1}=F_{t}+\alpha\left(X_{t}-F_{t}\right)$

$F_{t+1}=F_{t}+\alpha\left(e_{t}\right)$

2. Double Exponential

Smoothing: Brown's

persamaan sebagai

berikut :

$S_{t}^{\prime}=\alpha \cdot X_{t}+(1-\alpha) \cdot S_{t-1}^{\prime}$

$S_{t}^{\prime \prime}=\alpha \cdot S_{t}^{\prime}+(1-\alpha) \cdot S^{\prime \prime}{ }_{t-1}$

$a_{t}=S_{t}^{\prime}+\left(S_{t}^{\prime}-S^{\prime \prime}{ }_{t}\right)=2 S_{t}^{\prime}-S^{\prime \prime}{ }_{t}$

$b_{t}=\frac{\alpha}{1-\alpha}\left(S^{\prime}{ }_{t}-S^{\prime \prime}{ }_{t}\right)$

$F_{t+1}=a_{t}+b_{t} m$

a. Double Exponential Smoothing : Holt's Two Parameter

b. Triple Exponential Smoothing
Persamaan smoothing kuadratis adalah ;

c. Triple Exponential Smoothing : Winter's Three ParameterTrend and Seasonality

Metode Winter's dapat digunakan untuk data musiman. Metode Winter's didasarkan 3 persamaan smoothing: satu untuk kestasioneran, satu untuk trend dan satu untuk musiman. Persamaan Winter's adalah;

$$
\begin{gathered}
S_{t}=\alpha \frac{X_{t}}{I_{t-1}}+(1-\alpha)\left(S_{t-1}+b_{t-1}\right) \\
b_{t}=\gamma\left(S_{t}-S_{t-1}\right)+(1-\gamma) b_{t-1}
\end{gathered}
$$

\subsection{Kebutuhan dan Kegunaan Peramalan}

Sering terdapat waktu senjang antara kesadaran akan peristiwa atau kebutuhanmendatang dengan peristiwa itu sendiri. Adanya waktu tenggang ini merupakan alas an utama bagi perencanaan dan peramalan. Jika waktu tenggang ini nol atau sangat kecil,maka perencanaan tidak diperlukan. Jika waktu tenggang ini panjang, dan hasil peristiwa akhir bergantung pada faktor-faktor yang dapat diketahui, maka perencanaan dapat memegang peranan penting. Dalam situasi seperti itu, peramalan diperlukan untuk menetapkan kapan suatu peristiwa akan terjadi atau timbul, sehingga tindakan yang tepat dapat dilakukan.

Selain hal di atas, kegunaan dari peramalan dapat terlihat pada saat pengambilan keputusan. Setiap orang selalu dihadapkan pada masalah pengambilan keputusan. Keputusan yang baik adalah keputusan yang didasarkan atas pertimbangan apa yang akan terjadi pada waktu keputusan itu dilaksanakan. Apabila kurang tepat ramalan yang kita susun atau yang kita buat, maka kurang baiklah keputusan yang kita ambil. Walaupun 


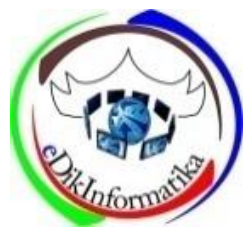

ISSN : 2407-0491

E-ISSN : 2541-3716

\section{Jurnal Edik Informatika}

Penelitian Bidang Komputer Sains dan Pendidikan Informatika

V1.i1(64-69)

demikian perlu disadari bahwa suatu ramalan adalah tetap ramalan, di mana selalu ada unsur kesalahan. Sehingga yang paling diperhatikan adalah usaha untuk memperkecil kemungkinan kesalahan tersebut.

\subsection{Langkah-langkah Peramalan} Lagkah-langkah

dalam

metode peramalan adalah:

1. Mengumpulkan data

2. Menyeleksi dan memilih data

3. Menganalisa data

4. Menentukan metode yang digunakan

PENGUMPULAN DAN PENGOLAHAN

DATA

\subsection{Gambaran Umum Perusahaan}

Pabrik Roti SANIA merupakan salah satu unit usaha menengah (UKM) dikota Padang, Sumatera Barat yang bergerak dibidang pengolahan makanan berbasis tepung terigu yang didirikan pada tahun 2002 oleh bapak Tedy Gunawan. Pabrik Roti Sania Bakery adalah pabrik yang memproduksi berbagai jenis roti seperti roti tawar, manis, roti isi coklat, roti isi keju, roti isi mentega, roti isi nenas.

Pada saat ini buk Sania mempunyai karyawan sebanyak 50 orang, karyawan tersebut diberi gaji oleh Buk Sania dengan gaji UMR senilai Rp1.400.000,-/ orangnya.

Roti Sania Bakery di distribusikan ke berbagai tempat, baik dipasarkan ke tokotoko kecil maupun besar, ke pasar, diswalayan maupun ke luar kota padang. Daerah utama pemasaran roti Sania yaitu Payakummbuh, Bukit tinggi, Batu sangkar, Damasraya, Lubuk Alung dan Maninjau. Selain itu roti Sania juga dipasarkan dilaur kota padang seperti diMuaro Bungo, Tebo, dan Bangko Provinsi Jambi. Bagi masyarakat kota padang bisa langsung membeli ke pabriknya maupun disorder oleh Sania Bakery..

berkaitan dengan masalah yang sedang diteliti, dengan cara mempelajari literature, referensi serta teori yang berhubungan dengan penelitian ini. Dalam hal ini data sekunder yang diperoleh dari perusahaan antara lain:

a) Data kebutuhan bahan baku

b) Data permintaan produk

c) Data sejarah dan perkembangan perusahaan

\section{a. Data demand Produk SANIA Bakery (dalam buah)}

Tabel 3.1 data permintaan

\begin{tabular}{|c|c|c|c|c|c|c|c|c|c|c|c|}
\hline \multirow{2}{*}{ Periode } & \multicolumn{10}{|c|}{ Produlu } & \multirow[b]{2}{*}{ Total } \\
\hline & \multicolumn{5}{|c|}{ 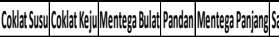 } & zail Kaya Panjijng & SPanjange & LatatPanjang || & & & \\
\hline Januan & 15000 & 58000 & 136500 & 78000 & 1222000 & 3550 & 6630 & 117000 & 780 & 117 & 1885800 \\
\hline Febuari & 15000 & 57000 & 13000 & 77000 & 125000 & 3300 & 43000 & 110000 & 730 & 110 & 1868300 \\
\hline Maret & 16000 & 57000 & 135000 & 72000 & 123000 & 3450 & 34500 & 12000 & 710 & 130 & 1853505 \\
\hline April & 14900 & 56500 & 14000 & 73000 & 120000 & 24300 & 34200 & 10000 & 700 & 120 & 1796000 \\
\hline Mei & 13000 & 54000 & 13000 & 76000 & 1210000 & 34000 & 35000 & 123000 & 650 & 123 & 18111400 \\
\hline Juni & 15000 & 60000 & 132000 & 7300 & 123000 & 3000 & 32000 & 11100 & 600 & BDO & 1749100 \\
\hline Juil & 14000 & 50000 & 135000 & 73000 & 1234000 & 3240 & 32100 & 122000 & 550 & 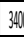 & 1858000 \\
\hline Agustus & 145000 & 53000 & 13000 & 75000 & 125000 & 3500 & 32000 & 123000 & 500 & 30 & 1855930 \\
\hline September & 13900 & 55500 & 131000 & 73000 & 123000 & 32885 & 31200 & 110000 & 500 & 30 & 1831496 \\
\hline Oktober & 15000 & 55000 & 132000 & 77500 & 1240000 & 35452 & 32000 & 11000 & 565 & 20 & 1770002 \\
\hline November & 165000 & 55000 & 134000 & 76500 & 1240000 & 32000 & 31000 & 120000 & 450 & 321. & 1800100 \\
\hline Desember & 17000 & 5400 & 132000 & 76000 & 124000 & 31200 & 32000 & 123000 & 40 & 20 & 1894200 \\
\hline
\end{tabular}

\section{b. Data Bahan Baku}

$$
\begin{aligned}
& \checkmark \text { Tepung }=50 \mathrm{sak} / \mathrm{hari} \\
& \text { X } 26=1300 \mathrm{sak} / \mathrm{bulan} \\
& \checkmark \text { Telur }=10 \\
& \text { karpet/hari (30 butir) X } 26 \\
& =260 \mathrm{karpet} / \mathrm{bulan} \\
& \checkmark \text { Gula }=100
\end{aligned}
$$

Inilah jumlah bahan baku yang dibutuhkan oleh perusahaan SANIA Bakery untuk memproduksi roti dalam sebulan.

proses Verivikasi untuk melihat peta control produk Pada Perusahaan Sania Bakery. 


\section{Jurnal Edik Informatika}

Penelitian Bidang Komputer Sains dan Pendidikan Informatika

$$
\text { V1.i1(64-69) }
$$

Dan akan menghasilkan Peta Kontrolnya seperti dibawah ini :

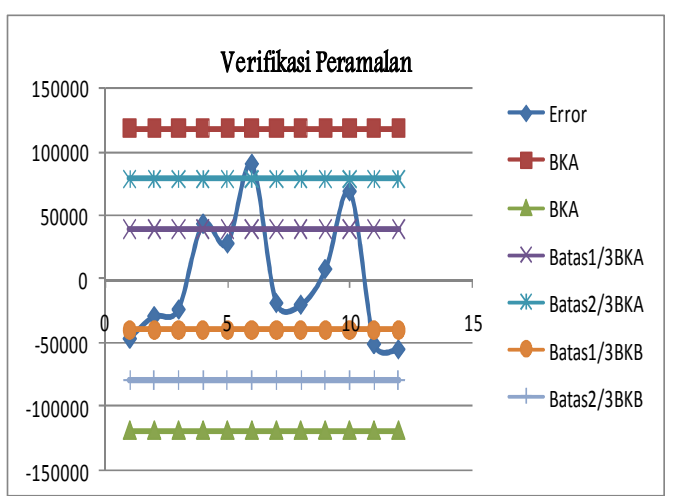

Gambar 3.1 Peta Kontrol

\section{c. Pengolaha dengan POM QM}

i. POM Win 3 dengan Metode Moving Average

a. Buka Program POM Win 3 pada Menu Modul kemudian pilih Forecasting

\begin{tabular}{|c|c|}
\hline POM for Windo & ws to accompany Heizer/Render's Opera \\
\hline File Edit View & Module Format Iools Window Help \\
\hline 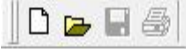 & Aggregate Planning \\
\hline Arial & Assembly Line Balancing \\
\hline & Assignment \\
\hline & Breakeven/Cost-Volume Analysis \\
\hline & Capital Investment \\
\hline POM for Windows & Decision Analysis \\
\hline & Forecasting \\
\hline & Inventory \\
\hline
\end{tabular}

b. Klik file pilih New akan muncul beberapa pilihan klik Time Series Analysis

\begin{tabular}{|c|c|c|}
\hline row for Wridols: & & \\
\hline \multicolumn{3}{|c|}{ 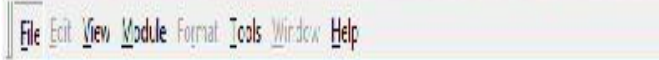 } \\
\hline 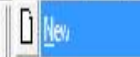 & & ITme Belistandyis \\
\hline a gpan & $(t+1)$ & 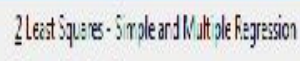 \\
\hline 10 & & 3Fayessic Prjector \\
\hline Desace & (Il| $\mid 5$ & Lerowanyisis \\
\hline
\end{tabular}

c. Pilih jenis periode yang diperlukan

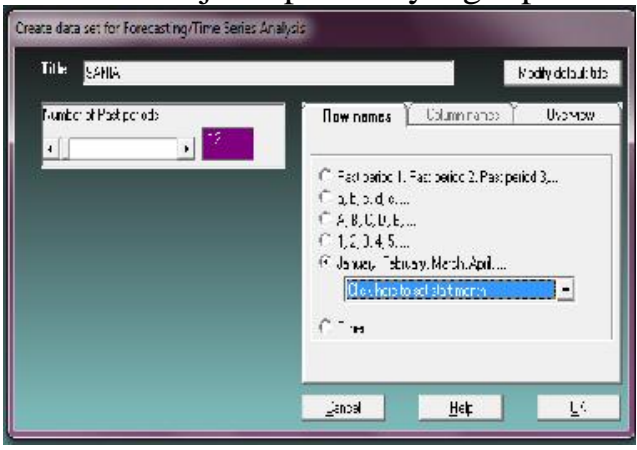

Tabel 3.2 Output metode miving average 2

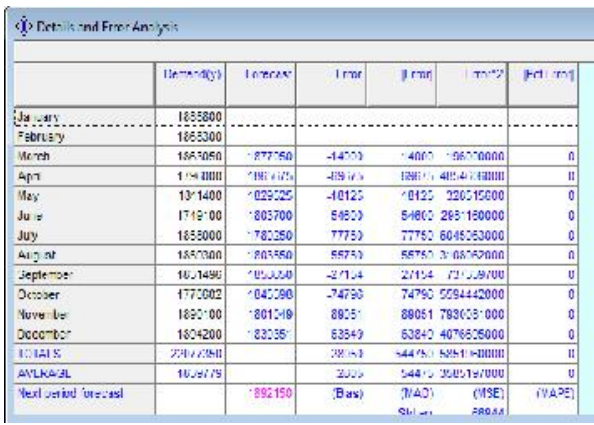

d. Menginput Data

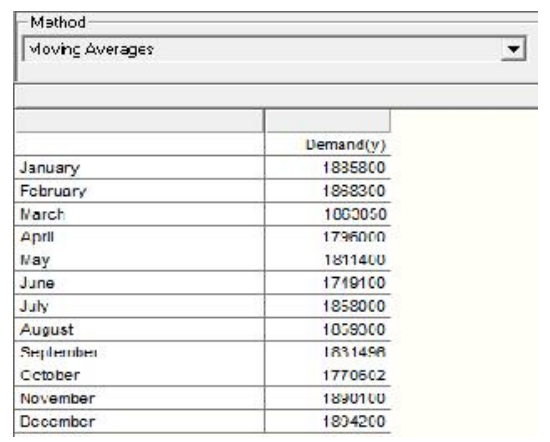

e. Kemudian klik Solve

f. Untuk melihat grafik atau peta kontrol maka pilih Graph, maka akan muncul seperti yang di bawah : 
Penelitian Bidang Komputer Sains dan Pendidikan Informatika V1.i1(64-69)

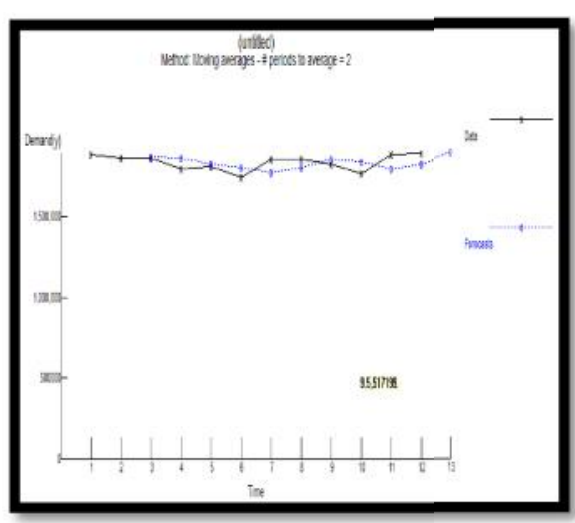

Gambar 3.2 grafik peramalan

\section{ANALISA HASIL}

A. Peramalan permintaan dengan POM win 3

Dari hasil pengolahan data yang menggunakan POM Win 3 dengan metode Moving Average (MA) diperoleh hasil peramalan produksi periode selanjutnya yaitu 1.893.380/buah dengan metode (WMA) Weighted Moving Average 2 diperoleh hasil peramalan produksi periode selanjutnya sebanyak 1.893.380/buah

Dari hasil pengolahan data demand yang diambil dengan melakukan survey lapangan pada Pabrik Roti Sania Bakery, didapatkan hasil, baik dengan menggunakan program POM QM ataupun Ms. Excel masing-masing metode menghasilkan hasil forecast/peramalan yang hampir sama. Untuk menentukan metode mana yang akan dipakai dalam peramalan penjualan maupun permintaan roti SANIA, maka dipakailah metode yang memiliki SEE

Tabel 4.1 Perbandinga nilai SEE

\begin{tabular}{|c|c|c|}
\hline Metode & SEE & Ket \\
\hline MA 2 & 63115.382 & \\
\hline WMA 2 & 62835.589 & \\
\hline Konstan & 46083.545 & $*$ \\
\hline ES & 54956.291 & \\
\hline
\end{tabular}

\section{KESIMPULAN DAN SARAN \\ 5.1 KESIMPULAN}

Dengan mengetahui jumlah permintaan produk yang dihasilkan oleh perusahaan, maka akan semakin mudah perusahaan meramalkan jumlah penjualan pada periodeperiode berikutnya. SANIA Bakery adalah salah satu contoh perusahaan yang dijadikan objek penelitian untuk meramalkan jumlah permintaan pada periode berikutnya. Dari pengolahan yang dilakukan diketahui jumlah permintaan terhadap produk roti SANIA yaitu 1.893.380,-. Hasil ini didapatkan dari pengolahan data dengan menggunakan Merode MA dan WMA. Peramalan untuk periode selanjutnya akan diramalkan mengalami penstabilan jumlah permintaan karena dapat terlihat pada grafik permintaan

\subsection{SARAN}

Dalam penyusunan laporan penelitian ini sebaiknya menggunakan data permintaan produk dengan mempertimbangkan berbagai aspek seperti bahan baku, dan jumlah penjualan produk dalam satuan waktu tertentu.

\section{DAFTAR PUSTAKA}

Antarikso, Tjoko.1994. Manajemen Produksi. Jakarta: Erlangga.

Ballou, R.H., Business Logistic Management, ed.3, Prentice-Hall International Inc., Englewood Cliffs, 1992.

Assauri, S. 1984. Teknik dan Metode Peramalan Penerapannya Dalam Ekonomi dan Dunia Usaha. Jakarta: Lembaga Penerbit Fakultas Ekonomi UI.

Makridakis. 1993. Metode dan Aplikasi Peramalan. Jakarta: Bina Aksara. 